\title{
Determinants of Division of Household Labor in Emerging Country: Evidence from Vietnam
}

\author{
Linh Hoai Do ${ }^{1}$, Trang Thu Bui ${ }^{2}$, Viet Anh Le ${ }^{2}$, Anh Tram Nguyen ${ }^{2}$, Huy Quang Nguyen ${ }^{2}$, Phuong Thu Do ${ }^{2}$ \\ ${ }^{1}$ School of Banking and Finance National Economics University 207 Giai Phong Road, Hai Ba Trung District, Hanoi City, \\ 100000 , Vietnam. \\ ${ }^{2}$ School of Advanced Educational Programs National Economics University 207 Giai Phong Road, Hai Ba Trung District, \\ Hanoi City, 100000, Vietnam.
}

*Corresponding author: Assoc.Prof. PhD, Linh Hoai Do

Received 26 April 2020;

Accepted 1 May 2020;

Published 05 May 2020;

\begin{abstract}
:
The research aims to analyze determinants of the division of household labor in Vietnam. Research model and hypotheses are developed based on the Theory of Planned Behavior - TPB (Icek Ajzen, 1985) with primary data from questionnaires survey. With 295 respondents during the period from November 2019 to April 2020, the study utilizes SPSS 20.0 software to test research model and hypotheses. The results show that "The Intention of Household Labor Division" is significantly affected by "Attitude", along with "Subjective Norms" (Gender Viewpoint) and "Perceived Behavioral Control"; the weakest determinants influencing "The Intention of Household Labor Division" comprise "Subjective Norms" (Friend), "Subjective Norms" (Family) and "Subjective Norms" (Social Environment). By contrast, "The Intention of Household Labor Division" influences "The Behavior of Household Labor Division" to the highest extent, followed by "Perceived Behavioral Control". Based on these findings, some recommendations are proposed to enhance the efficiency of the division of household labor, including (1) active involvement of government; (2) adjusting awareness; and (3) the right attitude.
\end{abstract}

Keywords: Division of household labor; Sociology; Attitude; Subjective Norms; Perceived Behavioral Control

\section{Introduction}

Family is recognized as the basic environment which has the biggest impact on human behaviors. The rules, habits and other activities conducted by husband and wife within the household scale deeply affect children's perception and action at present and in the future, leading to the widespread influence on the entire manhood of humanity. Owing to this cause, standards and proper behaviors in the family need installing as a role model for the future generations, building a civilized outlook. The fundamental of a family with full happiness is that the management of household chores gets unified by both husband and wife. Division of household labor has always been one of the most controversial issues on the globe in economics and social construction of gender identity aspects. Nevertheless, in reality, the division of unpaid works in the family remains inadequate to a greater or less degree. Specifically, according to the report of UNICEF, the average time of female individuals spent on house working is threefold greater than that of men since women utilize 17 hours per week taking care of their home while male individuals' figure is less than 6 hours weekly. This status may triple the risk of early contracting ailments such as diabetes, heart diseases, arthritis, and cancers due to the undertaking overload of household chores. Hence, women's opportunities of seeking and affirming position in the labor market, advancing expertise, health, psychology and leisure time as well as social activities are being restricted (UNICEF, 2018).
The unpaid work in the family consists of not only domestic tasks but also educating children, community jobs, financial management, and the right to make a decision on household issues. These doings require a proper allocation and arrangement in order to ensure an accomplished marriage and family life. The question fabricated is how to achieve that target, whether any objective and subjective effect directly or indirectly relates to the division of household labor or not. With the intention of tracking the solution for the query above, especially in case of Vietnam, the highly-populated region with distinct demographic characteristics, our scientific working group realizes the necessity of analyzing the allocation of family chores and have decided to investigate the topic "Determinants of Division of Household Labor in Emerging Country: Evidence from Vietnam".

\section{Literature Review}

\section{Definition of family}

Family is an assemblage of people who are tied together due to marriage, blood or foster relations, by which their rights and obligations to each other are raised (Clause 10, Article 8, Chapter 1, The Law on Marriage and Family in Vietnam, 2010). According Le Ngoc Hung and Pham Tat Dong (1999), these rights and obligations are performed in order to meet the individual needs of members and the social indispensable demand for human reproduction. Furthermore, family is the basic unit of society and 
the natural environment for the development and welfare of all members, especially the children (the United Nations, 1969). G.P Mendo (1949) assumed that family is a typical social group living in the same residence, working in cooperation and reproducing economically. This group encompasses the adults of both genders whose sexuality is recognized by the society, bearing one or many offsprings and also adopting children. Regardless of being investigated by many approaches, family remains such an ambiguous term that creates difficulties in generating a perfect definition. Along with the development of society, family varies gradually, proved by new diverse types such as single-family (only one parent and child), cohabiting couples, etc.

The family's value is the formation of important familial cognitions; it allows members to identify well-anticipated goals which are worth expecting, thereby eliminating personal conflicts for the sake of the collective. Once the value of the family is reflected in the communication process amongst people not only within the household but in society scale, people will perceive and perform their actions through familial value by all means. Synonymous with the exceptional value of family is the happiness it composes which is generated from generations to generations, ultimately becoming the well-acknowledged belief of mankind of family, the utmost particularly important institution in the world (Rokeach, 1973).

\section{Definition of household labor division}

Auguste Comte in the 19th century pioneered a sociological concept: "The division of labor is the specialization of labor tasks in order to perform the function of social stability and development and to strengthen the close relationship between individuals and the social order. The division of labor is not merely a specialization of labor, but actually a process associated with social division, stratification and inequality". Influenced by this concept, Émile Durkheim (1893) stated that the typical element in society of organized solidarity is the division of labor. The higher the society in organizing the division of labor, the denser the network of dependencies; in the meantime, the specialization ability becomes the beginning in the personal development of individuals. The division of labor in society can occur on the basis of various natural characteristics of the labor entities, as well as on the characteristics of socio-economic development.

The division of household labor is the responsibility in family works of both husband and wife, and other family members to perform functionalities such as health care, education, etc. in order to ensure the existence and stable development of the family. Along with that, the labor division within the household is the element that constitutes gender roles in the family and society. The division of labor by genders does not merely depend on the differences in biological characteristics between men and women but is always associated with habits, thoughts and opinions about the position and role of men and women society. This study will concentrate on the division of household labor between the spouses, the objectives take the main responsibilities for household labor and clearly perform gender roles in family and society.

\section{Theory of Planned Behavior for Division of Household Labor}

Icek Ajzen (1985) introduced the theory of planned behavior with the title: "From Intentions to Actions: A Theory of Planned Behavior". The TPB model was developed from the TRA model and is considered as a complete version of TRA by adding the variable "Perceived Behavioural Control" which is the third direct determinant of "Behavioral Intention", beside "Attitude" and "Subjective Norms". "Perceived Behavioural Control" explains the extent of difficulty for an individual to perform a given behavior from the available resources and opportunities. Behaviors within a controllable range often dominate the human behavior tendency. On the contrary, the tendency does not appear for hindered and uncontrollable behaviors, even when the individual's attitude towards the behavior is positive.

"Attitude" is defined as the way to perceive an individual's specific behavior. The intimate relationship between attitude and outcome is also specified by the TPB model. Suppose an individual believes that a behavior will produce a desirable result, that individual will have a positive attitude towards the behavior and vice versa, if an individual believes that the behavior will lead to an undesirable outcome, the attitude of that individual will become negative. There are two factors measuring "Attitude": "Behavioral Beliefs" and "Outcome Evaluation". "Behavioral Beliefs" is the belief that may be perceived when a certain behavior is performed. "Outcome Evaluation" is defined by the evaluation of whether the behavior outcome is positive or negative.

"Subjective Norms" is the impact on an individual from a reference group. According to Ajzen's definition: "Subjective norms are social pressures on an individual who is expected to behave in a manner to comply with common views". "Subjective Norms" are measured by two factors: "Normative Beliefs" and "Motivation to Comply". People identify their "Normative Beliefs" as the actions allowed and not allowed. It may also be understood that "Normative Beliefs" is the thoughts of the reference group about whether an individual should or should not perform a behavior. The more references support, the more individuals perform the behavior. The more references oppose, the more individuals hesitate to take actions. "Motivation to Comply" explains an individual's compliance or non-compliance with the social norms. If the social norms are considered as the proper standard, that individual will comply with them. Conversely, if the social norms are considered as the wrong thing, that individual will not comply with them.

\section{Research model and hypotheses}

Our research model and hypotheses are conducted based on the Theory of Planned Behavior Behavior Theory - TPB (Icek Ajzen, 1985). Independent variables including "Demographics", "Attitude", "Subjective Norms" and "Perceived Behavioral Control" are used to examine "Intentions of Household Labor Division". Two main defined factors which have an effect on "Behavior of Household Labor Division" are: "Intention of Household Labor Division" and "Perceived Behavioral Control".

The research group uses demographic variables including gender, age, living area, income level, education level. From these variables, the hypotheses were designed as below:

H1a: There are differences in the division of household labor in different genders

H1b: There are differences in the division of household labor in different ages

H1c: There are differences in the division of household labor in different living areas

H1d: There are differences in the division of household labor in different income levels 
H1e: There are differences in the division of household labor in different academic levels

"Attitude" is recognized as the way an individual perceives a certain behavior (Icek Ajzen, 1985). Attitudes include behavioral assessments, whether it is good or bad as well as an individual's desire to perform it (Leonard, 2004). We defines the "Attitude" towards the division of household labor by the evaluation: support or non-support the division of household labor from the individuals. The research group has the following hypotheses:

H2: Attitude for the division of household labor has a positive impact (+) on The Intention of Household Labor Division.

"Subjective Norms" is social pressure felt to perform a behavior or not to perform a behavior (Icek Ajzen, 1985). People who have a positive subjective norm for a behavior are more likely to engage in a behavior (Taylor and Todd, 1995; Han, 2010). Many studies have concluded that "Subjective Norms" are an important determinants in predicting intention and behavior (Baker, 2007; Dean, 2012; Ha and Janda, 2012; Kumar, 2012). With this sociological research topic, our research group predicts that the influence of the factor "Subjective Norms" is very large. "Subjective Norms" will affect "The Intention of Household Labor Division" from many aspects. We decided to separate the "Subjective Norms" into four subfactors, including "Family", "Friends", "Social Environment" and "Gender Viewpoint":

H3a: Family has a positive impact $(+)$ on The Intention of Household Labor Division

H3b: Friend has a positive impact $(+)$ on The Intention of Household Labor Division

H3c: Social Environment has a positive impact (+) on The Intention of Household Labor Division

H3d: Gender Viewpoint has a positive impact (+) on The Intention of Household Labor Division

"Perceived Behavioral Control" is an individual's perceived ease or difficulty of performing the particular behaviour. It is assumed that "Perceived Behavioral Control" is determined by the total set of accessible control beliefs. Some factors that affect this factor include health, personal awareness, personal time availability and ability to perform tasks, etc.

H4a: Perceived Behavioral Control has a positive impact (+) to The Intention of Household Labor Division

H4b: Perceived Behavioral Control has a positive impact (+) to The behavior of Household Labor Division

Theory of Planned Behaviour (Icek Ajzen, 1985) has indicated that an individual's behavior is taken or not due to "Behavioral Intention" and "Perceived Behavioral Control" in combination. Inheriting this theory, Sheppard (1998) pointed out that between "Intention" and "Actual Behavior" existed an intimate connection. Therefore, our group formed the following hypotheses:

H5: The Intention of Household Labor Division has a positive impact (+) on The behavior of Household Labor Division.

Fig.1 summarizes our research model of Determinants of Division of Household Labor in Vietnam:

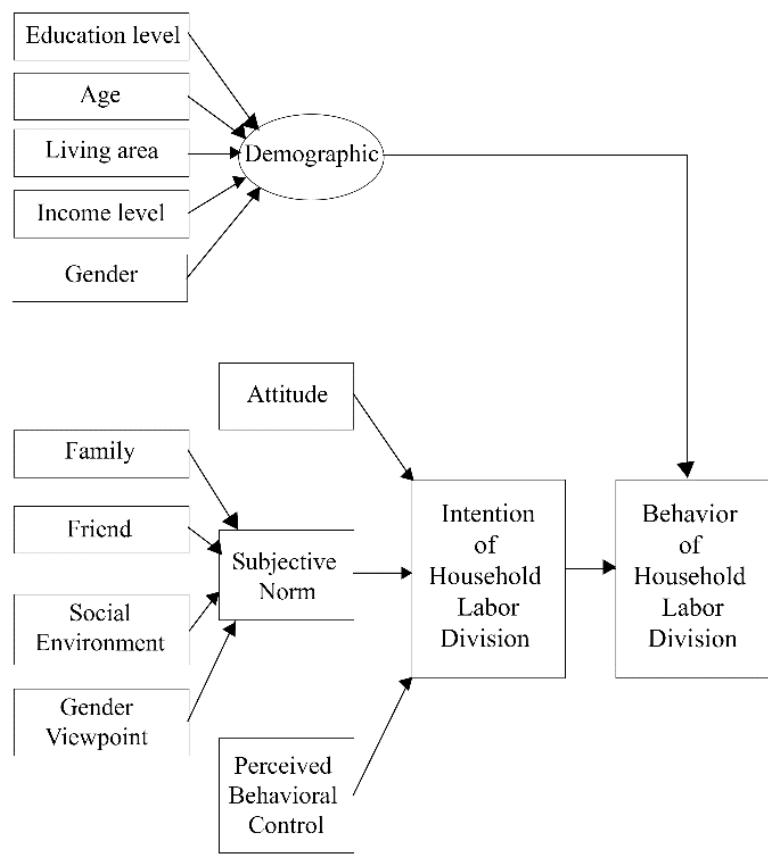

Figure 1: Proposed research model

\section{Methodology}

\section{Qualitative research}

Expert interviews are conducted before and after making questionnaires to make proper adjustments. We conducted a combination of in-depth interviews and focused on discussion with the group of 5 marriage and family experts, 2 labor and social experts, and 1 economic expert. All 8 participants interviewed and discussed by the authors about the most complete scale construction in which adjusted, supplemented or eliminated the observed variables used to measure main determinants.

\section{Quantitative research}

To test the developed hypotheses, we constructed the questionnaire survey with three parts: the first part was to gather demographic characteristics of the sample, the second part was to collect information about the situation of household labor division in Vietnam and the third part involved a range of questions measuring the variables presented in the research model. The questionnaire was adapted and re-checked by the in-depth interviews in order to examine the content, wording, accuracy, and clarity. The questionnaire was based on the observation variables and designed by Likert scale with 5-point rating system from strongly disagree (1) to strongly agree (5).

The population of this study was all families in Vietnam, though conducting the survey in such a large population is impractical. Therefore, in this study, we set the minimum sample size at 165 with 33 variables, which is deemed adequate according to Bollen rule (1989). This rule states that the sample rate on the observed variable must be at least 5:1. We conducted surveys in the North of Vietnam which is one of the most important socioeconomic areas in Vietnam. Because of demographic diversity from age, academic level, income level, etc., the North was an appropriate sample.

Primary data were collected from survey-questionnaires designed to answer research questions and performed in both by 
online and hard copy. The hard copy was launched in six Northern provinces and the online survey was implemented in the Northern region via many different channels such as email, social networks and printed handout. After a month of survey period (December 2019), we obtained 320 responses. After selection process, 25 responses were rejected due to the lack of important information; 295 responses were valid for analysis.

\section{Data analysis}

The research uses SPSS 20.0 software to test the model and hypotheses of the study. Specifically, Cronbach Alpha coefficient measured the reliability of each scale and Exploratory Factor Analysis (EFA) evaluated the convergence value and discriminant value of the variables. Analysis results show that all variables meet the requirements of reliability and value. Our group also uses regression analysis to examine the research hypotheses and assess the degree of influence of independent variables to the dependent variable. We check the differences between the dependent variables according to the control variables by Anova.

\section{Results and Discussion}

\section{Statistical description}

There were 320 questionnaires handed out, we collected 320 ones. After filtering, the remaining 295 questionnaires meet the requirements. The official sample size is 295 observed for inclusion in the analysis.

\section{Table 1: Statistics description of}

"The intention of household labor division (YD)"
In terms of gender, there is a difference in the number between men and women. Specifically, the number of men in this survey was 150 , accounting for $50.8 \%$ compared to 145 females, which accounted for $49.2 \%$.

In terms of ages, out of 295 people surveyed, there were 100 people aged $18-34$, which accounted for 33.9\%; The age of 35-55 occupies $52.9 \%$, with 156 people; The age of 55 occupies $13.2 \%$ with 39 people.

In terms of income, a total of 295 people surveyed, mostly concentrated at a income of 5 million to 10 million at a rate of $35.3 \%$, less than 1 million have 9 people at $3.1 \%$, from 1 million to 5 million have 50 people at $16.9 \%$ rate, from 10 million to 18 million have 99 people at a rate of $33.6 \%$ and the income level above 18 million has 33 people at a rate of $11.2 \%$.

In terms of education level, the percentage of people with a university level of $44.7 \%$ corresponds to 132 , followed by the proportion of people under university level there were 79 people with a rate of $26.8 \%$ and finally above university level with a rate of $28.5 \%$ corresponding to 84 people.

In terms of the geographical distribution, there is no too great difference between the percentage of survey participants. In the study sample included 295 observations, thanks to geographical conditions, the survey subjects came from the most Red River delta, which accounted for $44.4 \%$ respectively with 131 people. The following is the North-Western area with $33.2 \%$ respectively 98 people and finally the North-Eastern area accounted for $22.4 \%$ with 66 people

\begin{tabular}{|l|l|l|l|l|l|}
\hline \multicolumn{2}{|c|}{} & Frequency & Percent & Valid Percent & Cumulative Percent \\
\hline \multirow{3}{*}{ Valid } & Not Intended & 105 & 35.6 & 35.6 & 35.6 \\
\cline { 2 - 6 } & Intended & 190 & 64.4 & 64.4 & 100.0 \\
\cline { 2 - 6 } & Total & 295 & 100.0 & 100.0 & \\
\hline
\end{tabular}

Source: Authors' data analysis, 2020

With the dependent variable "The intention of household labor division", the average value of 0.644 shows that $64.4 \%$ of the respondents intend to divide labor in the family.

Table 2: Statistics description of

"The behavior of household labor division"

\begin{tabular}{|l|l|l|l|l|l|}
\hline & $\mathrm{N}$ & Minimum & Maximum & Mean & Std. Deviation \\
\hline HV1 & 295 & 1 & 5 & 3.37 & 1.038 \\
\hline HV2 & 295 & 1 & 5 & 3.31 & 1.065 \\
\hline HV3 & 295 & 1 & 5 & 3.44 & 1.031 \\
\hline HV4 & 295 & 1 & 5 & 3.41 & 1.078 \\
\hline HV5 & 295 & 1 & 5 & 3.45 & 1.042 \\
\hline $\begin{array}{l}\text { Valid N } \\
\text { (listwise) }\end{array}$ & 295 & & & & \\
\hline
\end{tabular}

Source: Authors' data analysis, 2020

The assessment score for the behavioral scale is also quite high, with the average of the evaluation score from 3.31 to 3.45 and the standard deviation from 1.031 to 1.078 , showing that the volatility of the evaluation point is quite low. The results showed that the majority of the respondents had the division of labor activities in the family ranging from "Occasionally" to "Frequently". This shows that the division of labor in the family is not a new issue but it has not been widely disseminated and the frequency of committing acts is not much.

\section{Statistical results}

\section{Reliability test via Cronbach's alpha}

The Cronbach Alpha results of the good factor shows that the observed variables listed are excellent, reflecting the characteristics of that factor. High quality tests are important to evaluate the reliability of data supplied in an examination or a research study. At the first run, most factors satisfy the requirements of the test. Attitude factor (TD) has a Cronbach's alpha value of 0.926; Subjective Norms-Family factor (GD) has a Cronbach's alpha value of 0.897; Subjective Norms-Friend factor (GD) has a Cronbach's alpha value of 0.909 ; Subjective Norms-Social Environment factor (XH) has a Cronbach's alpha value of 0.929; Subjective Norms-Gender Viewpoint factor (DG) has a Cronbach's alpha value of 0.906; Perceived Behavioral Control factor (KSHV) has a Cronbach's alpha value of 0.905 ; The behavior of Household Labor Division factor (HV) has a Cronbach's alpha value of 0.933 . 
All Cronbach's alphas are greater than 0.6; and all factors have Corrected Item-Total correlation values of greater than 0.3 .

Table 3: Summary of the reliability test for accessibility (Cronbach's alpha)

\begin{tabular}{|l|l|l|}
\hline Factor & Number of variables & Cronbach's Alpha coefficient \\
\hline Attitude & 3 & 0.926 \\
\hline Subjective Norms-Family & 3 & 0.897 \\
\hline Subjective Norms-Friend & 3 & 0.909 \\
\hline Subjective Norms-Social Environment & 4 & 0.929 \\
\hline Subjective Norms-Gender Viewpoint & 3 & 0.906 \\
\hline Perceived Behavioral Control & 4 & 0.905 \\
\hline The behavior of Household Labor Division & 5 & 0.933 \\
\hline
\end{tabular}

Thus, after Cronbach's alpha validation, none of the observation variables are removed prior to inclusion in the EFA - exploratory factor analysis.

Source: Authors' data analysis, 2020

\section{Exploratory Factor Analysis (EFA)}

Exploratory factor analysis was used to assess the convergence and differentiation values of the scales. The analysis results show that all scales meet the requirements of reliability and value. Specifically, Cronbach alpha of all 4 scales shows high reliability (> 0.7). EFA was implemented separately for the dependent variable (accessibility) and concurrently executed with 20 variable observations measuring 3 independent variables. The results of the EFA analysis show that the scales meet the requirements for deductible factors, total cumulative error more than $50 \%$ and load factor more than $>0.5$ (Table 3$)$.

\section{Table 4: Factor Loadings}

\begin{tabular}{|l|l|l|l|l|l|l|}
\hline & \multicolumn{2}{l|}{ Component } & \multicolumn{5}{l|}{} \\
\hline & 1 & 2 & 3 & 4 & 5 & 6 \\
\hline CQMTXH2 & .870 & & & & & \\
\hline CQMTXH1 & .858 & & & & & \\
\hline CQMTXH4 & .837 & & & & & \\
\hline CQMTXH3 & .765 & & & & & \\
\hline KSHV1 & & .920 & & & & \\
\hline KSHV4 & & .902 & & & & \\
\hline KSHV2 & & .851 & & & & \\
\hline KSHV3 & & .838 & & & & \\
\hline TD1 & & & .941 & & & \\
\hline TD3 & & & .926 & & & \\
\hline TD2 & & & .924 & & & \\
\hline CQGD3 & & & & .892 & & \\
\hline CQGD1 & & & & .851 & & \\
\hline CQGD2 & & & & .793 & & \\
\hline CQBB3 & & & & & .862 & \\
\hline CQBB1 & & & & & .821 & \\
\hline CQBB2 & & & & & .814 & \\
\hline CQQDG2 & & & & & & .838 \\
\hline CQQDG3 & & & & & & .832 \\
\hline CQQDG1 & & & & & & .806 \\
\hline Ex12c10n & & & & & & \\
\hline
\end{tabular}

Extraction method: Principal Component Analysis.

Rotation method: Varian with Kaiser Normalization.

Rotation converged in 6 iterations.

Source: Authors' data analysis, 2020

The first factor: includes the observed variables CQMTXH1 to CQMTXH4, representing the Subjective Norms - Social Environment factors;

The second factor: includes the observed variables KSHV1 to KSHV4, representing Perceived Behavioral Control factors;

Table 6: Hypothesis Results
The third factor: includes observed variables TD1 to TD3, representing Attitudes

The fourth factor: includes the observed variables CQGD1 to CQGĐ3, representing the Subjective Norms - Family factors; Fifth factor: includes observed variables CQBB1 to CQBB3, representing the Subjective Norms - Friend) factors;

Sixth factor: includes the observed variables CQQDG1 to CQQDG3, representing the Subjective Norms - Gender Viewpoint factors.

\section{Hypothesis testing}

Table 5: Binary Logistic Regression Results

Dependent variable: The Intention of household labor division

\begin{tabular}{|l|l|l|l|l|l|l|l|}
\hline \multicolumn{2}{|c|}{ Variables in the Equation } \\
\hline \multicolumn{2}{|c|}{} & B & S.E. & Wald & df & Sig. & $\operatorname{Exp(B)}$ \\
\hline \multirow{3}{*}{$1^{\text {Step }}$} & BB & 470 & 203 & 5.350 & 1 & 021 & 1.600 \\
\cline { 2 - 8 } & GD & 461 & 209 & 4.876 & 1 & 027 & 1.586 \\
\cline { 2 - 8 } & XH & 432 & 210 & 4.212 & 1 & 040 & 1.540 \\
\cline { 2 - 8 } & DG & 638 & 205 & 9.672 & 1 & 002 & 1.893 \\
\cline { 2 - 8 } & KSHV & 627 & 163 & 14.788 & 1 & 000 & 1.872 \\
\cline { 2 - 8 } & TD & 818 & 202 & 16.467 & 1 & 000 & 2.265 \\
\cline { 2 - 8 } & Constant & 9.700 & 1.310 & 54.845 & 1 & 000 & 000 \\
\hline
\end{tabular}

a. Variable(s) entered on step 1: BB, GD, XH, DG, KSHV, TD.

Source: Authors' data analysis, 2020

Based on the above table, it can be seen that "Perceived Behavioral Control", "Attitude", "Friends", "Family", "Social environment", "Gender view" all increase the probability of occurrence of the intention to assign family labor, in which "Attitude" has the strongest impact with $\mathrm{B} 6=0.818$ shows that when there is a positive attitude, "The Intention of household labor division" of each individual also increases. . The factor "Gender view" with B4 $=0.638$ represents an increase in the intention to assign family labor based on belief in each person's perceptions of the unique characteristics of each gender. In addition, the factor "Behavior control" with $\mathrm{B} 5=0.627$ indicates that each individual also tends to increase the family's intention of household labor division through easier perception when doing this behavior. when both physically and mentally qualified. Similarly, the impact is less strong $(\mathrm{B} 1=0.470, \mathrm{~B} 2=0.461, \mathrm{~B} 3=0.432)$ but when affected by the labor division behavior of relatives, friends, and social environment. Each person also tends to increase the intention of division of labor in the family. 


\begin{tabular}{|c|c|c|c|c|c|c|c|c|}
\hline \multicolumn{9}{|c|}{ Coefficients $^{\mathrm{a}}$} \\
\hline \multicolumn{2}{|c|}{ Model } & \multicolumn{2}{|c|}{ Unstandardized Coefficients } & \multirow{2}{*}{$\begin{array}{l}\text { Standardized } \\
\text { Coefficients } \\
\text { Beta }\end{array}$} & \multirow[t]{2}{*}{$\mathrm{t}$} & \multirow[t]{2}{*}{ Sig. } & \multicolumn{2}{|c|}{ Collinearity Statistics } \\
\hline & & B & Std. Error & & & & Tolerance & VIF \\
\hline \multirow[t]{3}{*}{1} & (Constant) & 2.102 & .158 & & 13.335 & .000 & & \\
\hline & YD1 & .580 & .104 & .298 & 5.592 & .000 & .915 & 1.093 \\
\hline & KSHV & .296 & .050 & .315 & 5.925 & .000 & .915 & 1.093 \\
\hline
\end{tabular}

Source: Authors' data analysis, 2020

From Table 6 above, With B1 $=0.580$ shows that in the context of other factors unchanged, when intending to assign family labor (YD = 1), "The Behavior of household labor division" increased by 0.580 units. . In fact, each individual tends to act according to his/her intention, so this is considered an essential factor, strongly affecting the division of labor in the family so to change the division of labor habits in the direction of reducing the situation of non-division of labor, there should be solutions contributing to forming the intention of division of labor in the family. With B2 =
0.296, the condition of other factors does not change, when increasing "Perceived Behavioral Control" by 1 unit, the "The Behavior of household labor division" increases by 0.296 units. Moreover, according to ANOVA, the research model is significant $(\mathrm{p}=0.00)$ with the adjusted $\mathrm{R}$ Square $=0.238$, therefore independent variables affect $23.8 \%$ the change of the dependent variable, the remaining $76.2 \%$ is due to variables outside the model and random errors. The Durbin-Watson value $=1.738$, so, there is no superlative chain correlation in the model.

Table 7: Hypothesis Results

\begin{tabular}{|l|l|l|l|l|}
\hline Code & Hypotheses & Regression coefficient & Sig & Conclusion \\
\hline H2 & $\begin{array}{l}\text { Attitude for the division of labor in the family has positive } \\
\text { impact (+) to The Intention of household labor division. }\end{array}$ & 0.818 & 0.000 & Accepted \\
\hline H3a & $\begin{array}{l}\text { Family has positive impact (+) to The Intention of household } \\
\text { labor division }\end{array}$ & 0.461 & 0.027 & Accepted \\
\hline H3b & $\begin{array}{l}\text { Friend has positive impact (+) to The Intention of household } \\
\text { labor division. }\end{array}$ & 0.470 & 0.021 & Accepted \\
\hline H3c & $\begin{array}{l}\text { Social Environment has positive impact (+) to The Intention of } \\
\text { household labor division }\end{array}$ & 0.432 & 0.002 & Accepted \\
\hline H3d & $\begin{array}{l}\text { Gender Viewpoint has positive impact (+) to The Intention of } \\
\text { household labor division }\end{array}$ & 0.638 & 0.000 & Accepted \\
\hline H4a & $\begin{array}{l}\text { Perceived Behavioral Control has positive impact (+) to The } \\
\text { Intention of household labor division }\end{array}$ & 0.627 & 0.000 & Accepted \\
\hline H4b & $\begin{array}{l}\text { Perceived Behavioral Control has positive impact (+) to The } \\
\text { behavior of household labor division }\end{array}$ & 0.296 & 0.000 & Accepted \\
\hline H5 & $\begin{array}{l}\text { The Intention of household labor division has positive impact } \\
(+) \text { to The behavior of household labor division }\end{array}$ & 0.580 & \\
\hline
\end{tabular}

Source: Authors' data analysis, 2020

Table 8: Verify differences in the behavior of household labor division by gender

\begin{tabular}{|l|l|l|l|l|}
\hline \multicolumn{2}{|l|}{ Sndependent Samples Test } & Levene's Test for Equality of Variances & t-test for Equality of Means \\
\cline { 3 - 5 } \multicolumn{2}{|l|}{} & F & & Sig. (2-tailed) \\
\hline \multirow{2}{*}{ HV } & & & \\
\cline { 2 - 6 } & Equal variances assumed & 13.764 & .000 & .000 \\
\hline
\end{tabular}

Test results show that Sig values. $=0.000<0.05$, so the variance of 2 overall is different. The $t$-test result in the line assuming unequal variance has value Sig. $=0.00<0.05$ shows that there are differences in behavior based on gender.

Table 9: Verify the difference in the behavior of household labor division by ages, living areas, income levels and education levels

\begin{tabular}{|l|l|l|l|l|}
\hline Code & Hypothesis & Sig. (Levene test) & Sig (ANOVA test) & Conclusion \\
\hline H1b & $\begin{array}{l}\text { There is a difference in the division of } \\
\text { labor in the family at different ages }\end{array}$ & $0.459>0,05$ & $0,020<0,05$ & Accepted \\
\hline H1c & $\begin{array}{l}\text { There is a difference in family division of } \\
\text { labor in different living areas }\end{array}$ & $0.346>0,05$ & $0,000<0,05$ & Accepted \\
\hline H1d & $\begin{array}{l}\text { There are differences in the division of } \\
\text { household labor in different income } \\
\text { levels }\end{array}$ & $0,450>0,05$ & $0,015<0,05$ & Accepted \\
\hline
\end{tabular}




\begin{tabular}{|l|l|l|l|l|}
\hline H1e & $\begin{array}{l}\text { There are differences in the division of } \\
\text { household labor in different education } \\
\text { levels }\end{array}$ & $0,078>0,05$ & $0,010<0,05$ & Accepted \\
\hline
\end{tabular}

(Source: Summary of analysis results on SPSS)

\section{Results discussion}

According to the Reliability test results via Cronbach's alpha, independent variables were proved to be reliable. First, based on the demography data, we can see the average rating point of women (Mean=4.15) is 1.5 times more than that of Men (Mean=2.67). The above findings are based on the fact that women tend to favor division of household labor more than men due to a clearer perception of the inequality in family life. This result is similar to the study of Mick Cunningham (2008). Besides, we also notice the difference in the division of household labor in families at different ages. Data show that the age group from 35 to 55 has the highest labor division (Mean=3,1875), followed by the age group from 18 to 34 (Mean=2,9902) and the lowest is the group above 55 years old (Mean=2.8211). This suggests that mostly older people will be less likely to divide household labor because people in this age group will not be responsible for household tasks. In addition, because their views and ideas are influenced by gender stereotypes, they suppose that the assignment of household duties to both spouses is not really necessary. This conclusion was mentioned in the study of Tran Quy Long (2007). The statistical data also shows that the average value of agreeing to assign household tasks of the surveyed people from the Red River Delta is highest with Mean=3.65 while the lowest are those from Northwestern with Mean=3.12. Based on the results of the analysis, we can see the difference in the division of household labor when considering the geographical factors. The majority of households from the Red River Delta have a better quality of life, greater access to information and gender awareness, so they can easily change and improve. For the surveyors from the Northwestern and Northeastern regions, as pointed out in the theoretical basis, the people here still have remnants of backward ideas in the ideology. Despite there are some propaganda measures to raise awareness about gender equality, division of household labor is not clearly expressed here. Differences in family division behavior by region also were concluded in the research of John Knodel, Manh Loi Vu and Tuan Huy Vu (2009). In addition, it is easy to see that the group of people with income level over 18 million VND/month) tends to have the highest household labor division behavior with Mean=3.61, while in contrast, the group with income level less than 1 million VND/month shows a different result: household labor division behavior is very low with Mean=2.44. The three income groups from 1-5 million $\mathrm{VND} /$ month to $10-18$ million $\mathrm{VND} /$ month have the equivalent of division of labor, respectively represented by the Mean of 3.30, 3.38 and 3.46. This is a demonstration that the behavior of household labor division is affected by the income factor. This conclusion is similar to the study of Susanne Fahlén in 2016 and Tran Quy Long in 2007. It can be explained that people with a high income level have many opportunities and conditions to approach trends and newer perspectives, from which they will be more open to contemporary issues. Moreover, the income problem greatly affects the quality of family life, when the financial problems in the family become stable, the concern about paid jobs will be reduced. Instead, they will have more time and more responsibilities for unpaid family work. Finally, the data also show the average value of behavior tends to go up by educational level, the higher the education level, the higher the tendency to divide household labor.
It shows clearly that the group of under university level has the lowest labor division with Mean=3.16, followed by the university level with Mean=3.40. The highest is the group of above university level with Mean=3.60. People who are in the higher education group have higher frequency of labor division in the family than other groups. Explaining these data, the university level and above university level groups have a high awareness of the roles, capacities and responsibilities of each member in the family. Highly educated people are more progressive in their gender awareness equality and the practice of family division of labor is a manifestation of this. This result is similar to the study of Susanne Fahlén (2016).

Second, data explored that "Attitude" is the factor that has the strongest impact on the dependent variable "The Intention of household labor division". The results of the binary regression model show that, with a significance level of $\alpha=5 \%$, Beta value of Attitude factor is highest with B6 $=0.818$. This factor includes observations of attitudes toward household labor division such as "Supporting the division of family labor" (TD1), "The division of family labor is necessary." (TD2) and "Positive attitude when discussing the division of household labor" (TD3). Attitude is a way of seeing, evaluating and acting in a trend before an event. Attitudes that come from within are closely connected with the intention to perform the behavior. In fact, each person has a perception and propensity to act based on the attitude available to the involved audience. That is why among the factors that influence the intention of household labor division, the attitude towards household labor division is the most powerful factor. The more positive the attitude, the greater the intention to engage in the behavior. Gender viewpoint is the second most important factor affecting the intention of household labor division. According to the regression model result, with a significance level of $\alpha=5 \%$, Beta value of Gender View factor is $\mathrm{B} 4=0.638$. This factor includes observations such as "No gender imposition on the division of household labor" (CQQG1), "Both men and women need to share the family works with each others" (CQQDG2). and "Both men and women are equal in doing the family works" (CQQG3). Gender viewpoint is one of the factors that strongly influence the intention of household labor division. When each member of the family respects gender equality, placing himself or herself in an equal position with the other person, the intention of household labor division will easily arise. The next factor also influences the intention of household labor division, but is a bit weaker than those above factors. The regression model results show that, with the significance level of $\alpha=5 \%$, the Beta value of the Perceived Behavioral Control factor is B5 $=0.627$. Perceived Behavioral Control includes observations such as "Health" (KSHV1), "Individual ability" (KSHV2), "Time availability" (KSHV3) and "Responsibility for family" (KSHV4). The main reason that Perceived Behavioral Control influences the intention of household labor division is because when approaching a problem, everyone will consider their abilities and competencies before they intend to act. The weakest group of factors includes Family, Friends and Social Environment. The regression model results show that, with the significance level of $\alpha=5 \%$, the Beta value of the factors Family, Friends and Social Environment are $\mathrm{B} 1=0.470, \mathrm{~B} 2=0.461, \mathrm{~B} 3=0.432$ respectively. Because people live and are governed by social laws, so society also has a 
significant impact on the views, thoughts and actions of each individual. People tend to act like people around them, friends and relatives because they don't want to be too different from the community. However, because most people have their own opinions, the influence of these factors is only relative and reference, not too much of an intention of household labor division.

Third, "The Intention of household labor division" is the factor that has the strongest impact on the dependent variable "The Behavior of household labor division". The result of linear regression with $\mathrm{B} 1=0.580$ shows that when other factors remain unchanged, when intending to divide household labor ( $\mathrm{YD}=1)$, "The Behavior of household labor division" increased by 0.580 units. In fact, the intention is often a prerequisite for behavior. Individuals tend to act according to their own intentions, so this is considered an essential factor influencing the behavior of household labor division. Perceived Behavioral Control is the next factor that affects the dependent variable. With $\mathrm{B} 2=0.296$, the condition of other factors does not change, when increasing "Perceived Behavioral Control" by 1 unit, "The behavior of household labor division" increases by 0.296 units. The factors "Health" (KSHV1), "Individual ability" (KSHV2), "Time availability" (KSHV3) and "Responsibility for family" (KSHV4) positively affect the behavior of household labor division. When each person is fit and competent in some jobs, has time for family and is aware of their responsibilities, sharing household labor with their spouses will become easier.. Therefore, raising awareness about the role of factors such as health, individual ability, time availability and family responsibilities of each member will make spouses willing to share and respect each other in carrying out family tasks. More generally, it can be argued that "The Behavior of household labor division" will be escalate by increasing "The Intention of household labor division" and "Perceived Behavior control".

\section{Conclusion}

Based on the analysis of the determinants influencing the division of household labor in Vietnam, there are six determinants affecting the decision of dividing household labor including: (i) Perceived Behavioral Control; (ii) Attitude; (iii) Friends; (iv) Family; (v) Social Environment and (vi) Gender Viewpoint. The research group also propose some resolutions following the issues:

\section{Active involvement of government}

First and foremost, foster healthy public discourse via the open censure of gender equality violations or toxic stereotyping. Develop an exemplar of gender role, so that citizens may look to for family adjustments. Revamp the deeply-rooted communication and education that still view household tasks as woman-centric.

As for the Northwestern and North-Eastern minority, work to bring the model "Happy and equal family" to the front, and incentivize husbands to take on housework, reduce poverty, develop the economy sufficiently to the point where prosperity and equality will come for both men and women. Raise awareness for Northwestern and North-Eastern areas which have low economic growth and antiquated traditions that may rigidify social justice. In the job market, women are the socioeconomic and sociocultural underdog; therefore, policies on gender equality in the workplace and equality of opportunity are due. An impoverished working class of women cannot harbor a voice for familial empowerment

\section{Adjusting awareness}

The government should also emphasize the reach of propaganda since it can establish a sense of what is right from the get go. Creative and novel campaigns will challenge both the misguided notions about the division of labor within a household and further renew the bastion of women rights like the Women Union. At the same time, traditional means of dissemination like leaflets and posters are to be reinforced with messages dispelling labor division prejudice. It is also of no less importance that a new light be shone in the way that husbands and wives divide their household workload for a more satisfactory and fair approach on the women's end. At the end of the day, the general agenda of the propaganda should serve to instill in our young population a proper sense of labor division that can then pass on to the next generations, thereupon setting an example as early as possible.

For the budding generation, promote and propagate gender equality, especially to children since they will inherit the future. Set an early precedent with digital media and feminist movements, and more importantly, start as early as when they are in school. Additionally, being cognizant of the issue early on should extend to every household so that they may bring about changes in the family unit. This is the type of familial accountability that necessitates husbands being involved in child care and housekeeping to balance out the workload. Likewise, the image of the overworked mother should be reformed. Therefore, measures that fall on the government's shoulder are to be implemented to improve and change the underlying attitude of households on the division of home labor.

\section{The right attitude}

As surveyed and analyzed, attitude is an important factor leading to specific behaviors, so many households still do not assign or unreasonably assign home labor mainly result from their apathy and prejudice. Asian people in general as well as Vietnamese people in particular are too familiar with the image of the hardworking mother who spends 8-hour shifts at work and is still burdened with household chores and child care. If this situation continues, Vietnamese women will still have to suffer a lot from injustice and will be unable to speak up. Henceforth, citizens' mindsets should be adjusted and positively influenced and should be affected right from the school seat, even should be affected anytime, anywhere, to any degree.

While our research encountered barriers and limitations from the scope of the investigation, we still hold our belief in the contribution to the issue of division of household labor this research has made. Additionally, the research also proposed suggestions and recommendations focusing on adjusting the education framework and encouraging citizens to get rid of stereotypes and equalize gender roles. On one hand, limitations do exist. On the other hand, this is an opportunity for the topic to be further developed and researched within Vietnam in general and within Northern Vietnam in particular. Other research authors are able to conduct similar studies with other scales and other spaces so that research can be completed more comprehensively and more objectively. Future research needs to be clear about influencing groups of factors such as demographics, including age, income, region of residence, etc.; subjective norms such as the influence of thoughts from family and relatives; .... If applicable and responsive, the research will be more valuable.

\section{Conflicts of Interest}

"The author(s) declare(s) that there is no conflict of interest regarding the publication of this paper." 


\section{References}

[1] Bussarawan Teerawichitchainan, John Knodel, Manh Loi Vu, Tuan Huy Vu (2009), "Gender Division of Household Labor in Vietnam: Cohort Trends and Regional Variations", accessed on $10 / 2 / 2020$ on https://ink.library.smu.edu.sg/cgi/viewcontent.cgi?article $=1770 \&$ context $=$ soss_research.

[2] Catherine Sofer, Sayyid Salman Rizavi ,"The Division of Labour within the Household: Is There any Escape from Traditional Gender Roles?", accessed on 10/2/2020 on https://www.ifs.org.uk/conferences/sofer_paper.pdf.

[3] Claudia Geist, Philip N. Cohen(2011), "Headed towards Equality? Housework Change in Comparative Perspective", Journal of Marriage and Family, 73(4), 832-844.

[4] Chun Bun Lam, Susan M. McHale, and Ann C. Crouter (2012) "The Division of Household Labor: Longitudinal Changes and Within-Couple Variation", Journal of Marriage and Family, 74(5), 944-952.

[5] Diane Sainsbury (1996), "Gender, Equality and Welfare States", Cambridge University Press.

[6] Hoang Dinh Tuan (2007), "Mathematical Economics Model Theory", National Economics University Publisher.

[7] Ho Ngoc Cham (2015), "The unpaid work of women in rural families: Current situation and Effects", Journal of Sociology, 4(132), 81-90.

[8] International Labour Office. Bureau for Gender (2004), "Promoting Gender Equality: Guide on ILO Conventions and Recommendations of particular concern to Women workers" accessed on 14/2/2020 on https://books.google.com.vn/books?id=jwVnguZ0Ps8C\& pg=PR3\&lpg=PR3\&dq=Promoting+Gender+Equality:+ Guide+on+ILO+Conventions+and+Recommendations+o $\mathrm{f}+$ particular+concern+to+Women+workers $\% \mathrm{E} 2 \% 80 \% 9$ D\&source $=$ bl\&ots $=1 \mathrm{hxBTIHtab} \& \operatorname{sig}=\mathrm{ACfU} 3 \mathrm{U} 0 \mathrm{GnNJW}$ Qqb5UewO-

FJUmlTMjeGOmA\&hl=vi\&sa=X\&ved=2ahUKEwi_4pb j5-

foAhUCHaYKHVjqCdoQ6AEwA3oECAsQKw\#v=onep age \&q=Promoting $\% 20$ Gender $\% 20$ Equality $\% 3 \mathrm{~A} \% 20 \mathrm{Gui}$ de\%20on\%20ILO\%20Conventions\%20and\%20Recomm endations $\% 20 \mathrm{of} \% 20$ particular $\% 20$ concern $\% 20$ to $\% 20 \mathrm{Wo}$ men $\% 20$ workers $\% \mathrm{E} 2 \% 80 \% 9 \mathrm{D} \& \mathrm{f}=$ false.

[9] Leah Ruppanner (2008), "Fairness and Housework: A Cross-National Perspective", Journal of Comparative Family Studies, 509-526.

[10] Le Thi Kim Lan (2006), "Gender Labor Division in Bru Van Kieu community" accessed on $14 / 2 / 2020$ on http://luanan.nlv.gov.vn/luanan?a=d\&d=TTbGGSfCppB q2006.1.8\&e=--------vi-20--1--img-txIN-------\#.

[11] Luong Van Uc (2009), "Sociology”, National Economics University Publisher.

[12] Marta Domínguez-Folgueras (2012), "Is Cohabitation More Egalitarian? The Division of Household Labor in Five European Countries", Journal of Family Issues, 34(12), 1623-1646.
[13] Mick Cunningham (2008), “Influences of gender ideology and housework allocation on woman's employment over the life course", Social Scientific Research, 37(1): 254-267.

[14] Ng. Quang Quynh (2012), "Financial Audit", National Economics University Publisher.

[15] Nguyen Thi Hien (2016), "Gender Viewpoint in Vietnamese Household Division"; accessed on 10/2/12020 on http://ilssa.org.vn/vi/news/quan-diemgioi-trong-phan-chia-lao-dong-gia-dinh-o-viet-nam-168.

[16] Nguyen Thi Ngan Hoa (2013), "Gender Inequality within the Household and its Impacts on Women's Life in Mekong Delta", Journal of Social Science, 9(181), 1319.

[17] Pham Dai Dong (2008), "Population Statistics", National Economics University Publisher.

[18] Philip N. Cohen (2004) "The gender division of labor: "Keeping House" and Occupational Segregation in the United States", Gender \& Society, 18(2), 239-252.

[19] Ronald Inglehart, Pippa Norris, McGuire (2003), "Rising Tide:Gender Equality and Cultural Change Around the World", Cambridge University Press.

[20] Susanne Fahlén (2016), "Equality at home - A question of career? Housework, norms, and policies in a European comparative perspective", Demographic Research, 35(48), 1411-1440.

[21] Tran Hanh Minh Phuong (2017), "Household Decision Making in Gender Relationship in Mekong Delta", Science Magazine of Can Tho University, 50, 96-107.

[22] Tran Quy Long (2007), "Household Labor of Women in Rural Families", Journal of Sociology, 4, 82-89.

[23] Tran Thi Minh Thi (2018), "Family Values from Theoretical Approach and Social Issues in Vietnam" accessed on 14/3/2020 on https://vass.gov.vn/noidung/tintuc/Lists/KhoaHocCongN ghe/View_Detail.aspx?ItemID=43.

[24] Tran Thi Kim Thu (2008), "Sociology Investigation", National Economics University Publisher.

[25] Truong Dinh Chien (2014), "Marketing Research Textbook", National Economics University Publisher.

[26] Tine Kil \& Karel Neels (2016), "Gender Inequality in the Division of Housework over the Life Course: a European Comparative Perspective", Social and Political Science, 51-80.

[27] The European Commission's e-library with key publications dealing with gender equality.

[28] Vu Tuan Huy, Deborah S.Carr (2000), "Domestic Work Division within the Household", Journal of Sociology, 4(72), 43-52.

[29] Vu Manh Loi (2014), “Opinions about Gender Theory in Household Research" accessed on 14/3/2020 on http://www.vanhoahoc.vn/nghien-cuu/ly-luan-van-hoahoc/vhh-va-cac-khoa-hoc-giap-ranh/2684-vu-manh-loimot-so-quan-diem-ly-thuyet-ve-gioi-trong-nghien-cuugia-dinh.html.

[30] Yoav Lavee, Ruth Katz (2002), "Division of Labor, Perceived Fairness, and Marital Quality: The Effect of Gender Ideology", Journal of Marriage and Family, 64, 27-39. 